\title{
Zinc finger protein ZBTB20 expression is increased in hepatocellular carcinoma and associated with poor prognosis
}

Qing Wang ${ }^{1 \dagger}$, Ye-xiong Tan ${ }^{1 \dagger}$, Yi-bin Ren ${ }^{1 \dagger}$, Li-wei Dong ${ }^{1}$, Zhi-fang Xie ${ }^{2}$, Liang Tang ${ }^{1}$, Dan Cao ${ }^{1}$, Wei-ping Zhang ${ }^{2}$, He-ping $\mathrm{Hu}^{3}$ and Hong-yang Wang ${ }^{2^{*}}$

\begin{abstract}
Background: Our previous studies showed that ZBTB20, a new BTB/POZ-domain gene, could negatively regulate $\alpha$ feto-protein and other liver-specific genes, concerning such as bio-transformation, glucose metabolism and the regulation of the somatotropic hormonal axis. The aim of this study is to determine the potential clinical implications of ZBTB20 in hepatocellular carcinoma (HCC).

Methods: Quantitative real-time RT-PCR and Western blot analyses were used to detect expression levels of ZBTB20 in 50 paired HCC tumorous and nontumorous tissues and in 20 normal liver tissues. Moreover, expression of ZBTB20 was assessed by immunohistochemistry of paired tumor and peritumoral liver tissue from 102 patients who had undergone hepatectomy for histologically proven HCC. And its relationship with clinicopathological parameters and prognosis was investigated.

Results: Both messenger RNA and protein expression levels of ZBTB20 were elevated significantly in HCC tissues compared with the paired non-tumor tissues and normal liver tissues. Overexpressed ZBTB20 protein in HCC was significantly associated with vein invasion $(P=0.016)$. Importantly, the recurrence or metastasis rates of HCCs with higher ZBTB20 expression were markedly greater than those of HCCs with lower expression $(P=0.003, P=0.00015$, respectively). Univariate and multivariate analyses revealed that ZBTB20 overexpression was an independent prognostic factor for HCC. The disease-free survival period and over-all survival period in patients with overexpressed ZBTB20 in HCC was significantly reduced.
\end{abstract}

Conclusions: The expression of ZBTB20 is increased in HCC and associated with poor prognosis in patients with HCC, implicating ZBTB2O as a candidate prognostic marker in HCC.

\section{Background}

Hepatocellular carcinoma (HCC) is the fifth most-common malignancy in the world and is the third cause of cancer-related death worldwide. The development and progression of $\mathrm{HCC}$ is a complicated process involving multiple genes and several transforming steps $[1,2]$. The exact molecular mechanisms underlying hepatocarcinogenesis have not yet been elucidated. Therefore, searching for new $\mathrm{HCC}$ associated molecules may give some

\footnotetext{
* Correspondence: hywangk@vip.sina.com

+ Contributed equally

${ }^{2}$ Department of Pathophysiology, Basic Medicine Institute, Second Military

Medical University,800 Xiangyin Road, Shanghai, 200433, PR China

Full list of author information is available at the end of the article
}

clues to study the mechanism of HCC and provide prognostic value in clinical issues.

The BTB/POZ-ZF [Broad complex, Tramtrack, Bric a' brac (BTB) or poxvirus and zinc finger (POZ)-zinc finger] protein family comprises a diverse group of transcription factors. These factors are so named because of a distinct and unique $\mathrm{N}$-terminal BTB/POZ domain and $\mathrm{C}$-terminal DNA-binding zinc finger domains. These proteins have been demonstrated to participate in a wide variety of cellular functions including transcriptional regulation, cellular proliferation, apoptosis, cell morphogenesis, ion channel assembly, and protein degradation through ubiquitination-proteasome system [3-5]. A subset of $\mathrm{BTB} / \mathrm{POZ}$ proteins have been
C Biomed Central

(c) 2011 Wang et al; licensee BioMed Central Ltd. This is an Open Access article distributed under the terms of the Creative Commons Attribution License (http://creativecommons.org/licenses/by/2.0), which permits unrestricted use, distribution, and reproduction in any medium, provided the original work is properly cited. 
implicated in human cancer, and they include BCL-6 (Bcell lymphoma 6) [6-9], PLZF (promyelocytic leukemia zinc finger) [10-14], leukemia/lymphoma-related factor (LRF)/Pokemon [15-18], HIC-1 (hypermethylated in cancer-1) [19-23], NAC-1[24-29] and Kaiso [30-33].

ZBTB20 gene, also named DPZF [34], HOF [35], and ZNF288 [36], is a new member of the BTB/POZ-ZF family. It has two isoforms due to the alternative translation initiation, both containing an intact $\mathrm{N}$-terminal BTB domain and a C-terminal zinc finger domain [35]. Zbtb20 is preferentially expressed by hippocampal progenitors, and essential for hippocampal development [37].

In liver, our previous work showed that human ZBTB20 is expressed in fetal liver [34]. In mouse, Zbtb20 is developmentally up-regulated in postnatal liver, and acts as a key transcription repressor of AFP [38]. What's more, ZBTB20 may play an essential role in liver intrinsic functions, possibly through regulating genes such as P450 family members, glucose metabolism and the regulation of the somatotropic hormonal axis [39].

In the present study, we investigated the expression of ZBTB20 in HCC tissues and its potential association with clinicopathological features and post-resectional survival. Our results suggested that ZBTB20 overexpression can be used as an independent marker for the prognosis of patients with HCC.

\section{Methods}

Patients and liver specimens

Primary HCC tissue sample $(n=152)$ were randomly obtained from patients who underwent routine curative surgery at the Eastern Hepatobiliary Surgery Hospital between 2001 and 2007. The patients were not pretreated with radiotherapy or chemotherapy prior to surgery. Among them, 102 tissue samples were fixed in $10 \%$ formalin and embedded in paraffin for immunohistochemical analysis. The other 50 tissue samples were immediately frozen in liquid nitrogen and stored at $-80^{\circ}$ $\mathrm{C}$ after hepatectomy for western blotting and real-time RT-PCR. Table 1 shows the clinicopathological features of these patients. Additionally, normal liver specimens were obtained from 20 patients with hemangiomas of liver who underwent surgery. The 20 cirrhotic liver specimens were obtained from patients who underwent liver biopsy. The diagnoses were confirmed by histopathologic study. Tumor stage was determined according to the 2002 International Union Against Cancer TNM classification system [40]. Tumor differentiation was graded by the Edmondson grading system. Written informed consent was obtained from these patients, and the protocol for this study was approved by the Ethics Committee of the Eastern Hepatobiliary Surgery Hospital.
Table 1 Clinicopathological parameters of 152 patients with HCC

\begin{tabular}{|c|c|}
\hline Clinicopathological parameters variables & $\begin{array}{l}n, \text { range All patients } \\
(n=152)\end{array}$ \\
\hline \multicolumn{2}{|l|}{ Age(years) } \\
\hline$>50$ & 84 \\
\hline$\leq 50$ & 68 \\
\hline \multicolumn{2}{|l|}{ Gender } \\
\hline Male & 118 \\
\hline Female & 34 \\
\hline \multicolumn{2}{|l|}{ Virus } \\
\hline HBV & 124 \\
\hline $\mathrm{HCV}$ & 4 \\
\hline Both & 0 \\
\hline None & 24 \\
\hline \multicolumn{2}{|l|}{$\operatorname{AFP}(\mathrm{ng} / \mathrm{ml})$} \\
\hline$\leq 20$ & 36 \\
\hline$>20$ & 116 \\
\hline \multicolumn{2}{|l|}{ Liver cirrhosis } \\
\hline Yes & 108 \\
\hline No & 44 \\
\hline \multicolumn{2}{|l|}{ Pathological stage } \\
\hline । & 3 \\
\hline$\|$ & 13 \\
\hline III & 131 \\
\hline IV & 5 \\
\hline \multicolumn{2}{|l|}{ Tumour size $(\mathrm{mm})$} \\
\hline$>50$ & 112 \\
\hline$\leq 50$ & 40 \\
\hline \multicolumn{2}{|l|}{ Tumour multiplicity } \\
\hline Solitary & 121 \\
\hline Multiple & 31 \\
\hline \multicolumn{2}{|l|}{ Vein invasion } \\
\hline Absent & 127 \\
\hline Present & 25 \\
\hline \multicolumn{2}{|l|}{ Tumor encapsulation } \\
\hline Complete & 65 \\
\hline Uncomplete & 34 \\
\hline No & 53 \\
\hline
\end{tabular}

\section{Cells and cell culture}

L02, QSG7701, PLC/PRF/5, SMMC7721, HepG2, SK-Hep-1, WRL68, Hep3B, Huh7, HCCCLM3, and HCCC97L cell lines were obtained from American Type Culture Collection (Manassas, VA) or Cell bank of Chinese Academy of Sciences (Shanghai, China). All cells were cultured in DMEM (GiBco BRL, Life Technologies) with $10 \%$ fetal bovine serum at $37^{\circ} \mathrm{C}$ in a humidified $5 \%$ $\mathrm{CO}_{2}$ atmosphere.

\section{Immunohistochemistry}

Histological diagnoses of tumourous and non-tumourous formalin-fixed and paraffin-embedded tissues were 
confirmed on haematoxylin and eosin-stained sections. The tissue sections (3- $\mu$ m thick) were dewaxed, rehydrated and then immersed in methanol containing $0.3 \%$ hydrogen peroxide for $30 \mathrm{~min}$ to block endogenous peroxidase activity. Subsequently, the sections were heated in a pressure cooker filled with $10 \mathrm{mM}$ ethylenediaminetetracetic acid (EDTA) buffer ( $\mathrm{pH} \mathrm{8.0)}$ for $2 \mathrm{~min}$. After cooling, the sections were incubated in $1 \%$ blocking serum for $30 \mathrm{~min}$ to reduce nonspecific binding. Primary anti-ZBTB20 polyclonal antibodies[39] were diluted $1: 350$ and incubated with the sections at $4^{\circ} \mathrm{C}$ overnight. Following incubation with biotinylated secondary antisera, the streptavidin-biotin complex/horseradish peroxidase was applied. Finally, the visualization signal was developed with diaminobenzidine (DAB) and the slides were counterstained in hematoxylin.

Stained sections were evaluated in a blinded manner without prior knowledge of the clinical information using the German immunoreactive score, ImmunoReactive-Score (IRS). Briefly, the IRS assigns sub-scores for immunoreactive distribution (0-4) and intensity (0-3), then multiplies them to yield the IRS score. The percent positivity was scored as "0" (<5\%), " 1 " (5-25\%), "2" (25-50\%), “3” (50-75\%,), “4” (>75\%). The staining intensity was score as "0" (no staining), "1" (weakly stained), "2" (moderately stained), and "3" (strongly stained). The final ZBTB20 expression score was calculated with the value of percent positivity score plus staining intensity score, which ranged from 0 to 12 (Figure 1). We estimated IRS by averaging the values in eight fields at $\times 400$ magnification for each specimen. Intratumoral/peritumoral ZBTB20 expression was defined as follows: low expression (score 0-6/0-3) and high expression (score $>6 / 4-6$ ). Immunohistochemical analysis and scoring were performed by 2 independent investigators.

\section{Immunoreactive score}

\section{Staining distribution}

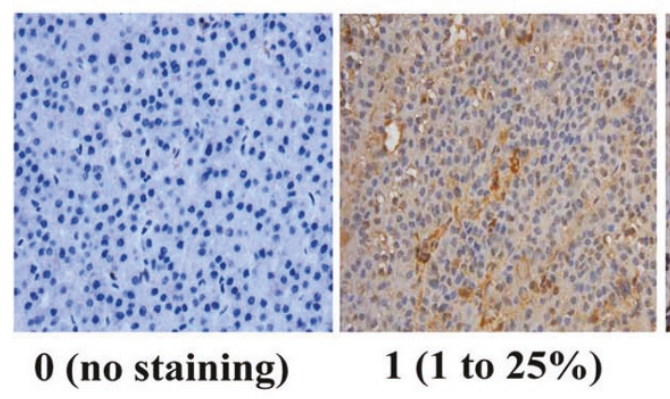

\section{Total score: distribution $\mathrm{x}$ intensity}
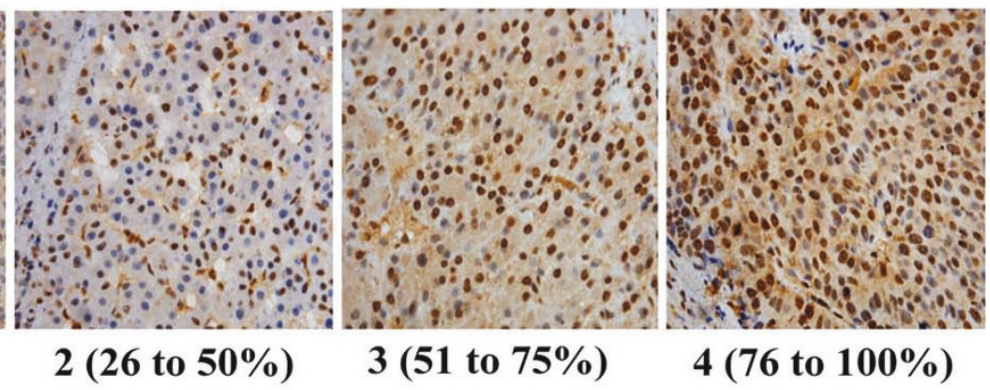

\section{Staining intensity}

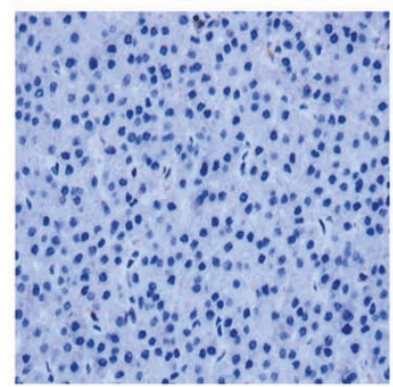

0, None

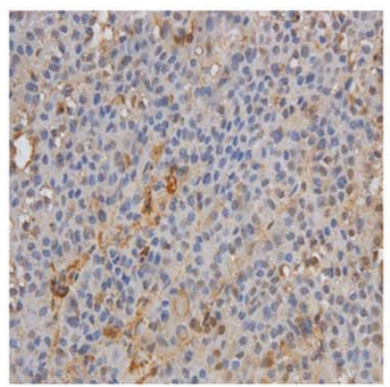

1, Weak

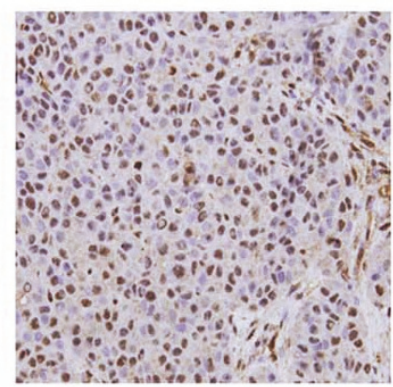

2, Moderate

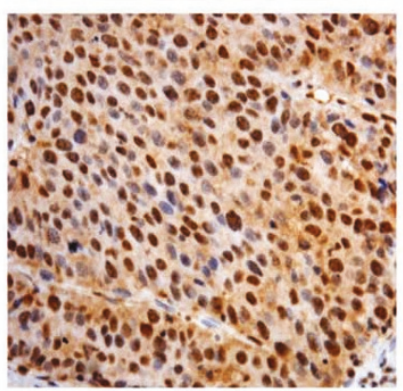

3, Strong

Figure 1 Typical scored immunohistochemical staining of liver tissue specimens. Formalin-fixed and paraffin-embedded tissues were incubated with primary anti-ZBTB20 polyclonal antibodies (diluted 1:350) at $4^{\circ} \mathrm{C}$ overnight. The visualization signal was developed with diaminobenzidine (DAB) and the slides were counterstained in hematoxylin. Total score was calculated from sub-scores of staining distribution (0-4) and intensity (0-3). 
RNA extraction, cDNA synthesis and real-time RT-PCR Total RNA was extracted from frozen tissue specimens (50-100 mg) using Trizol reagent (Invitrogen, Carlsbad, CA, USA), according to the manufacturer's protocol. The RNA was reverse transcribed using RT-PCR kits (Applied Biosystems, Foster City, CA, USA) with an oligo d (T) primer under standard conditions. Real-time ZBTB20 PCR amplification was performed in $1 \times$ Universal Master Mix (Applied Biosystems) with gene-specific primers and probe on the ABI Prism 7300 Sequence Detection System, according to the manufacturer's instructions. The $18 \mathrm{~s}$ rRNA levels were quantified as internal control to normalize the expression of each gene. Each reaction was repeated independently at least three times. The following primers were used: ZBTB20, sense 5'- ATGCTAGAACGGAAGAAACCCA -3', antisense 5'-TGTGAGCGTGAGAGTTTGTCA -3';18s, sense 5'-GGGAGGTAGTGACGAAAAA T-3' and antisense 5'-ACCAACAAAATAGAACCGCG-3'. Relative expression levels of genes were calculated and expressed as $2^{\Delta \mathrm{Ct}}$.

\section{Western blotting analysis}

Western blotting was performed as previously described [41]. In brief, the tissues or cells were lysed in RIPA buffer, sonicated, and protein concentrations calculated by Bicinchoninic acid (BCA) (Sigma). About $60 \mu \mathrm{g}$ protein samples were run on a $12 \%$ SDS-PAGE gel and transferred to a polyvinylidine difluoride membrane. Membranes were blocked for $1 \mathrm{~h}$ in Tris-buffered saline with $0.05 \%$ Tween 20 (TBST) containing 5\% skim milk. The membrane was probed with ZBTB20 antibody (dilution, 1:2000) overnight followed by washing triplely with TBST for $5 \mathrm{~min}$ and incubated with an IRDye 800CWconjugated secondary antibody. After being washed three times, the membrane was detected with LI-COR imaging system (LI-COR Biosciences). Mouse antihuman $\beta$-actin antibody (dilution, 1:1000; Santa Cruz) was applied as an internal control. The signal intensity of each band on scanned autoradiograms was analysed using LI-COR imaging system. We normalised each sample to the intensity of the $\beta$-actin band, and then estimated the value as an expression index.

\section{Follow-Up}

Follow-up data were obtained for all the 102 patients with immunohistochemical analysis. The follow-up period was defined as the interval from the date of operation to the date of death or the last follow-up. Deaths from other causes were treated as censored cases. Recurrence and metastasis were diagnosed by clinical examination, AFP measurement, liver ultrasonography, and computed tomography $(\mathrm{CT})$ scan. All patients were observed until December 2009, ranged from 29 to 103 months (median, 73 months). Overall survival (OS) was defined as the interval between the dates of surgery and death. Disease-free survival (DFS) was defined as the interval between the dates of surgery and recurrence; if recurrence was not diagnosed, patients were censored on the date of death or the last follow-up.

To determine factors influencing survival after operation, 13 conventional variables together with ZBTB20 expression were tested in 102 patients: age ( $\leq 50$ years $v \mathrm{~s}$ $>50$ years), gender, tumor size $(\leq 50 \mathrm{~mm} v s>50 \mathrm{~mm})$, serum AFP level ( $\leq 20 \mathrm{ng} / \mathrm{mL} v s>20 \mathrm{ng} / \mathrm{mL}), \mathrm{HBs} A g$ (positive $v s$ negative), Edmondson-Steiner grade (I-II $v s$ III-IV), liver cirrhosis (yes $v s$ no), tumor encapsulation (complete $v s$ uncomplete $v s$ no), vein invasion (yes $v s$ no), tumour multiplicity (solitary $v s$ multiple), TNM stage (I-II $v s$ III), recurrence (yes $v s$ no), metastasis (yes vs no), and ZBTB20 intratumoral/peritumoral protein expression level (high vs low).

\section{Statistical analysis}

A paired-samples t-test was used to compare the mRNA and protein expression of ZBTB20 between HCC tumorous and the pair-matched non-tumor tissues samples. The Pearsontest or Fisher's exact test was used to analyze the relationship between ZBTB20 expression and the clinicopathologic features. The correlation between the expression of ZBTB20 and AFP was explored using Spearman's correlation analysis. Survival curves were calculated using the Kaplan-Meier method and compared by the log-rank test. The Cox proportional-hazard regression model was used for univariate and multivariate analyses to explore the effect of the clinicopathological variables and ZBTB20 expression on survival. SPSS 16.0 software (SPSS Inc., Chicago, IL, USA) was used for all statistical analyses and a $p$ value $<0.05$ was considered significant.

\section{Results}

Increased Expression Levels of ZBTB20 Messenger RNA and Protein in Hepatocellular Carcinoma

Our previous work showed that ZBTB20 was developmentally up-regulated in liver and was a key repressor governing AFP gene transcription in postpartum liver, and may play an essential role in liver intrinsic functions by regulating genes such as P450 family members, glucose metabolism and the regulation of the somatotropic hormonal axis. To investigate the expression of ZBTB20 and its possible role in $\mathrm{HCC}$, we first detected the protein expression in three human normal liver cell line (L02, QSG7701, WRL68) and 8 HCC cell lines (PLC/ PRF/5, SMMC7721, HepG2, SK-Hep-1, Hep3B, Huh7, HCCCLM3, and HCCC97L). ZBTB20 was high expressed in most of the cells (Figure $2 \mathrm{~A}$, the whole image was shown in additional file 1). We further 


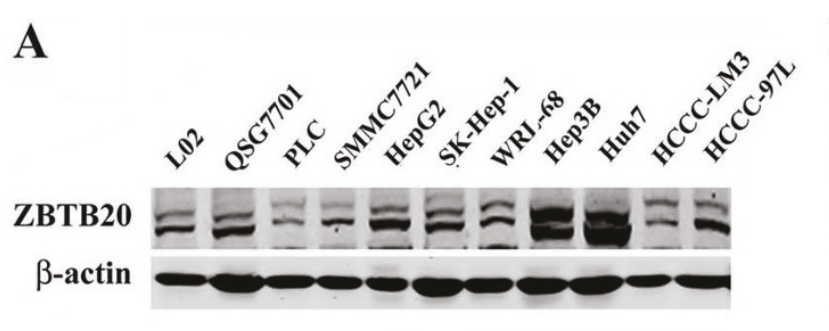

B
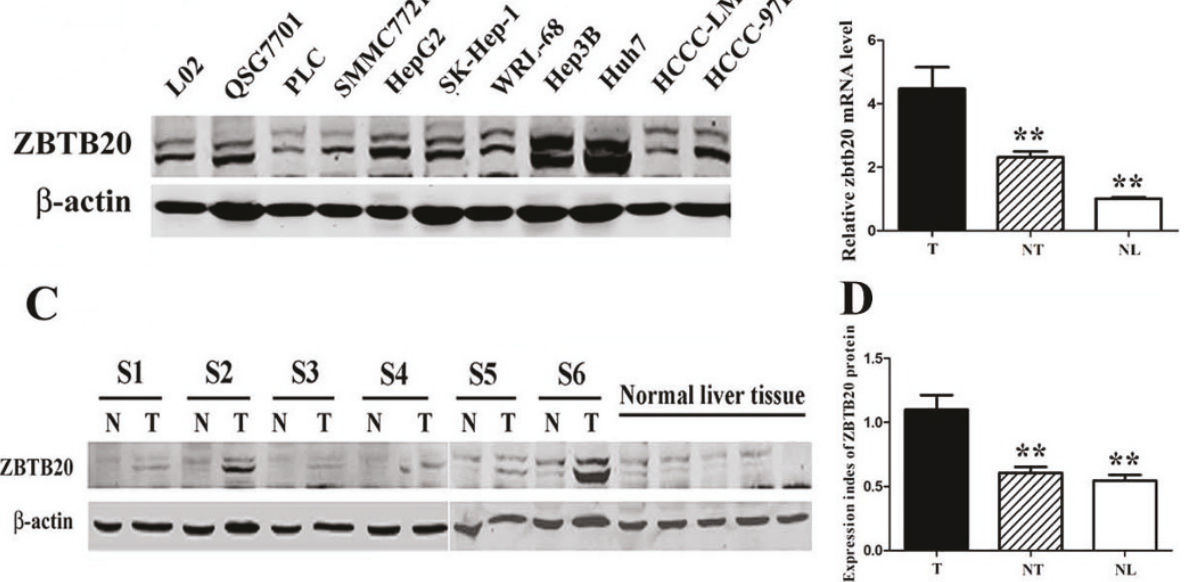

Figure 2 ZBTB20 expression in HCC tissues and HCC cell lines. A. Western blot analysis of ZBTB20 in HCC cell and normal liver cell lines. B. Evaluation of ZBTB20 mRNA in HCC. C. Western blot analysis of ZBTB20 in HCC and normal liver tissues. T Tumor tissue; NT non-tumor tissue; NL normal liver. D. Expression index of ZBTB20 protein. ZBTB20 protein expression level in HCC was significantly higher than those in NT (P< 0.001$)$. The data are representative of three independent experiments.**: T compared with NT or NL, $p<0.05$.

performed real-time RT-PCR for the transcriptional level of ZBTB20 from 50 frozen paired samples derived from patients who had undergone hepatectomy for histologically proven HCC. The mRNA level of ZBTB20 was significantly higher in 38 (76\%) HCC tissues (tumour; T) compared with the pair-matched nontumor tissues (NT). We calculated the copy number ratio of ZBTB20 mRNA/18s mRNA. This ratio was significantly higher in tumor samples than in NT samples $(4.47 \pm 2.71$ versus $2.32 \pm 0.64, P=0.006)$ (Figure $2 \mathrm{~B}$ ).

Next, the protein level of ZBTB20 in T and NT specimens of 50 HCC cases was analyzed by western blot analysis. ZBTB20 signal was found to be positive in all $\mathrm{T}$ samples, and in $78 \%$ of NT samples. The intensity of each protein band was normalised against the expression of $\beta$-actin in each sample, and this ratio was treated as an expression index. Consistent with mRNA expression, the protein level of ZBTB20 in HCC tumor tissues was also significantly higher than that in NT samples (1.81-fold on average, $P<0.001$ ) (Figure $2 \mathrm{C}$ ).

\section{Immunohistochemistry Analysis of ZBTB20 Expression and its Relationship with the Clinicopathological Parameters}

To investigate the effect and the prognostic value of ZBTB20, immunohistochemistry was used to assess the expression of ZBTB20 in the HCC tissues sections. It was showed that ZBTB20 staining was mainly in the nucleus of tumor cells, partly in the cytoplasm. ZBTB20 expression in normal hepatocytes from paratumoral tissue of hemangiomas of liver and cirrhotic liver were negative or weakly positive (Figure 3A,B), while mainly moderate or strong positive in $\mathrm{HCC}$ tumors (Figure 3C). Overall, 42 of the $102(41.2 \%)$ cases showed high expression (IRS over 6) ZBTB20 in the tumorous tissues, while 60 (58.8\%) of the cases showed low expression (IRS 0-6). Generally, ZBTB20 density was significantly higher in intratumoral tissues than in peritumoral tissues $(6.37 \pm 3.17$ versus $2.73 \pm$ $1.68, P<0.001$ ) (Table 2). Additionally, a sharp contrast was often observed between infiltrative tumorous areas of positive staining and the adjacent nontumorous area of negative staining (Figure 3D).

We analysed the relationship between ZBTB20 protein expression and clinical features of $\mathrm{HCC}$ by establishing two groups with high and low ZBTB20 expression respectively based on the results of immunohistochemistry analysis. As shown in Table 3, intratumoral ZBTB20 density were positively correlated with vein invasion, recurrence and metastasis. Meanwhile, patients with high peritumoral ZBTB20 density were prone to recurrence. There was no significant association between ZBTB20 expression and the other clinical features, such as age, gender, tumor size, serum AFP level, HBsAg, Edmondson-Steiner grade, liver cirrhosis, tumor encapsulation, tumour multiplicity or TNM stage.

Our past work showed that ZBTB20 negatively regulated AFP [38]. However, in this work, no correlation between serum AFP level and tissue ZBTB20 protein expression was found. Considering the possible discrepancy of serum and liver tissue AFP level, we examined possible relationship between tissue AFP staining level and ZBTB20 expression level in HCCs, adopting Spearman's correlation analysis. In 102 samples, 61.8\% cases 


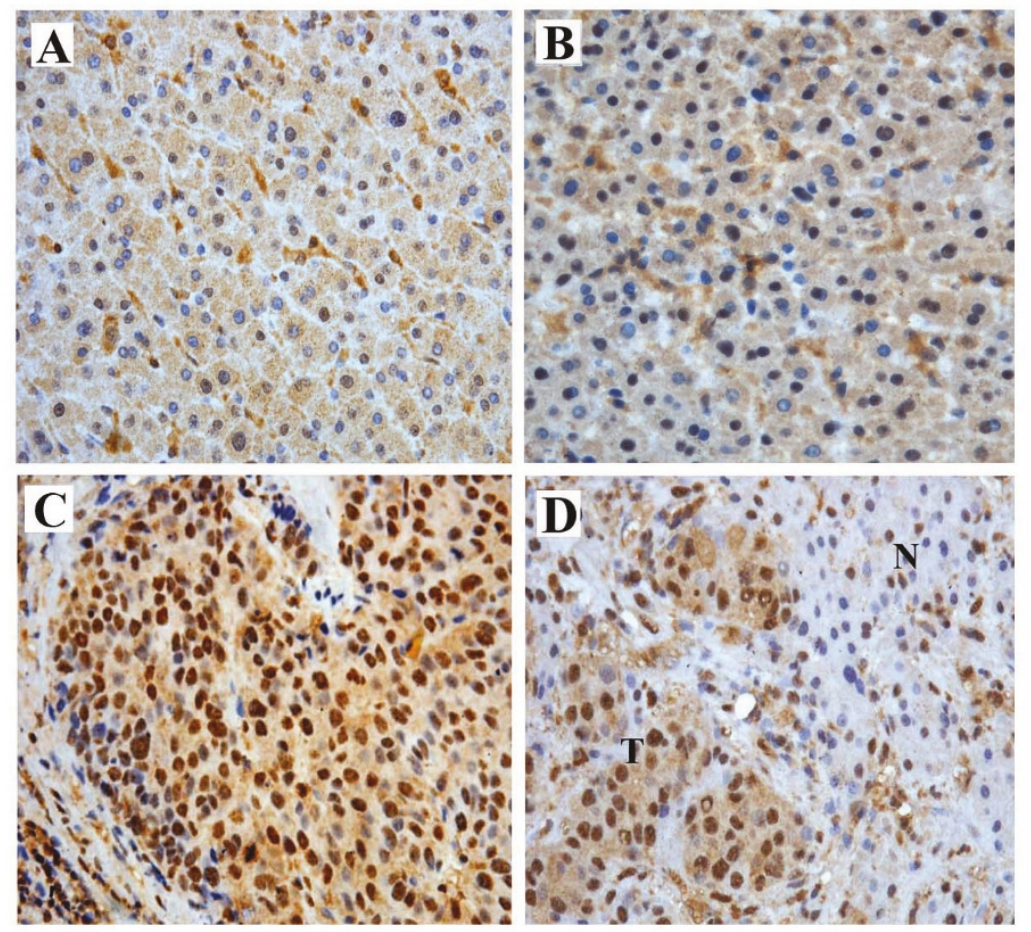

Figure 3 Immunohistochemistry detection of ZBTB20 expression in normal liver tissue, cirrhotic liver tissue, HCC (T) and in noncancerous hepatic tissues (N). A. Normal liver tissue. B. Cirrhotic liver tissue. The expression of ZBTB20 was weakly positive in hepatocytes. C. HCC cells stained strongly positive with a large granular pattern. D The boundary area between the tumor and non-tumor lesion. Hepatocytes adjacent to HCC lesion were stained with a small granular pattern. Original magnification, $\times 200$. T, tumor; N, Paired-nontumor tissue.

(63/102) showed high IRS of ZBTB20 with low IRS of AFP; $29.4 \%$ cases $(30 / 102)$ showed low IRS of ZBTB20 with high IRS of AFP; and 8.8\% cases (9/102) showed almost the same level of IRS. As shown in Figure 4, the ZBTB20 level was negatively correlated with the staining degree of AFP in HCCs $(r=-0.33, P=0.001)$, while the serum AFP level had no significant correlation with the tissue AFP IRS $(P=0.538)$.

\section{Correlation between ZBTB20 Expression and Prognosis}

At the time of the last follow-up, 74 patients had tumor recurrence, and 59 patients had died. The 1-, 3-, and 5year OS rates were $77.5 \%, 53.5 \%$, and $45.9 \%$,

Table 2 Average Density of Normal liver, Cirrhotic liver, Peritumoral and Intratumoral ZBTB20

\begin{tabular}{ccccc}
\hline staining & \multicolumn{3}{c}{ density } & p \\
\cline { 2 - 4 } & mean & Standard deviation & range & \\
\hline Normal liver & 1 & 0.93 & $0-3$ & $<0.001^{*}$ \\
Cirrhotic liver & 2.46 & 0.91 & $0-4$ & $<0.001^{* *}$ \\
Peritumoral & 2.73 & 1.68 & $0-6$ & $<0.001^{* * *}$ \\
Intratumoral & 6.17 & 3.17 & $0-12$ & $<0.001^{* * * *}$ \\
\hline
\end{tabular}

Abbreviations: * Normal liver tissue vs Cirrhostic liver tissue; ** Normal liver tissue vs Peritumoral; *** Normal liver tissue vs Intratumoral; ****Peritumoral vs Intratumoral. respectively; and the 1-, 3-, and 5-year DFS rates were $52.8 \%, 33.4 \%$, and $26.5 \%$, respectively. The median OS and DFS time were 18 months $(95 \% \mathrm{CI}, 1.06$ months to 34.94 months) and 6 months $(95 \% \mathrm{CI}, 3.98$ months to 8.01 months), respectively, for patients with high intratumoral ZBTB20 density (IRS over 6, as described in Materials and methods) and were statistically shorter than the median OS and DFS time for patients with low peritumoral ZBTB20 density [ 67 months (95\%CI, 52.53 months to 81.47 months) and 31 months $(95 \% \mathrm{CI}, 13.89$ months to 48.12 months), respectively ( $P=0.001$ and $P<0.001$, respectively; Figure $5 \mathrm{~A}$ and $5 \mathrm{~B})]$. Besides, patients with high peritumoral ZBTB20 had poor DFS (9 months vs 22 months, $P=0.002$; Figure $5 \mathrm{D}$ ), whereas peritumoral ZBTB20 was not associated with OS ( $\mathrm{P}=$ 0.225 ; Figure $5 \mathrm{C}$ )

Univariate Cox regression analyses determined that tumor size, serum AFP, TNM stage, tumor number, tumor encapsulation, vein invasion and intratumoral ZBTB20 expression were significantly associated with OS; while tumor size, HBsAg positive, TNM stage, tumor number, vein invasion and intratumoral/peritumoral ZBTB20 expression were associated with DFS. Furthermore, multivariate Cox regression analyses revealed that high intratumoral ZBTB20 was independent risk factor 
Table 3 Relationship Between Intratumoral and Peritumoral ZBTB20 and Clinicopathologic Features

\begin{tabular}{|c|c|c|c|c|c|c|}
\hline \multirow[b]{2}{*}{ Variable } & \multicolumn{2}{|c|}{ Intratumoral ZBTB20 } & \multirow[b]{2}{*}{$P$} & \multicolumn{2}{|c|}{ Peritumoral ZBTB20 } & \multirow[b]{2}{*}{$P$} \\
\hline & $\begin{array}{c}\text { High } \\
(\mathrm{n}=42,41.2 \%)\end{array}$ & $\begin{array}{c}\text { Low } \\
(\mathrm{n}=60,58.8 \%)\end{array}$ & & $\begin{array}{c}\text { High } \\
(n=42,41.2 \%)\end{array}$ & $\begin{array}{c}\text { Low } \\
(n=60,58.8 \%)\end{array}$ & \\
\hline Age(years) & & & 0.523 & & & 1.0 \\
\hline$\leq 50$ & 19 & 31 & & 20 & 30 & \\
\hline$>50$ & 23 & 29 & & 22 & 30 & \\
\hline Gender & & & 0.188 & & & 0.188 \\
\hline Male & 36 & 45 & & 36 & 45 & \\
\hline Female & 6 & 15 & & 6 & 15 & \\
\hline Tumor size $(\mathrm{mm})$ & & & 0.299 & & & 0.550 \\
\hline$\leq 50$ & 10 & 20 & & 11 & 19 & \\
\hline$>50$ & 32 & 40 & & 31 & 41 & \\
\hline \multicolumn{7}{|l|}{$\operatorname{AFP}(\mathrm{ng} / \mathrm{ml})$} \\
\hline$\leq 20$ & 10 & 16 & 0.745 & 11 & 15 & 0.892 \\
\hline$>20$ & 32 & 44 & & 31 & 45 & \\
\hline $\mathrm{HBsAg}$ & & & 0.302 & & & 0.106 \\
\hline Positive & 38 & 50 & & 39 & 49 & \\
\hline Negtive & 4 & 10 & & 3 & 11 & \\
\hline Pathological stage & & & $0.396^{*}$ & & & $1.0^{*}$ \\
\hline$|-| \mid$ & 1 & 5 & & 2 & 4 & \\
\hline III-IV & 41 & 55 & & 40 & 56 & \\
\hline Liver cirrhosis & & & 0.675 & & & 0.172 \\
\hline Yes & 31 & 42 & & 27 & 46 & \\
\hline No & 11 & 18 & & 15 & 14 & \\
\hline Tumor encapsulation & & & 0.235 & & & 0.446 \\
\hline Complete & 12 & 27 & & 13 & 26 & \\
\hline Uncomplete & 10 & 10 & & 9 & 11 & \\
\hline No & 20 & 23 & & 20 & 23 & \\
\hline Vein invasion & & & 0.016 & & & 0.161 \\
\hline Present & 13 & 7 & & 11 & 9 & \\
\hline Absent & 29 & 53 & & 31 & 51 & \\
\hline Tumour multiplicity & & & 0.064 & & & 0.589 \\
\hline Solitary & 25 & 46 & & 28 & 43 & \\
\hline Multiple & 17 & 14 & & 14 & 17 & \\
\hline TNM stage & & & 0.07 & & & 0.573 \\
\hline$|-| \mid$ & 22 & 5 & & 25 & 39 & \\
\hline III & 20 & 55 & & 17 & 21 & \\
\hline Recurrence & & & 0.003 & & & 0.001 \\
\hline Yes & 37 & 37 & & 38 & 36 & \\
\hline No & 5 & 23 & & 4 & 24 & \\
\hline Metastasis & & & 0.000 & & & 0.08 \\
\hline Yes & 27 & 16 & & 22 & 21 & \\
\hline No & 15 & 44 & & 20 & 39 & \\
\hline
\end{tabular}

Abbreviations: HBsAg, hepatitis B s antigen.

*Twenty-five percent of all the cells have expected count less than 5; Fisher's exact test.

for OS (relative risk $[R R]=1.952, P=0.016$ ) and DFS (RR $=2.094, P=0.003$ ) (Table 4). Besides, tumor size large than $50 \mathrm{~mm}$ and vein invasion were also independent predictors for the OS of HCC patients $(P=0.006$ and 0.086 , respectively; Table 4 ), while the others failed to show this independence.
Using 12 months as the cutoff value, all of the recurrences were divided into early recurrence, which is mainly from intrahepatic metastasis, and late recurrence, which is usually a result of a multicentric new tumor [42]. Patients with higher intratumoral ZBTB20 density were prone to have an early recurrence compared with 


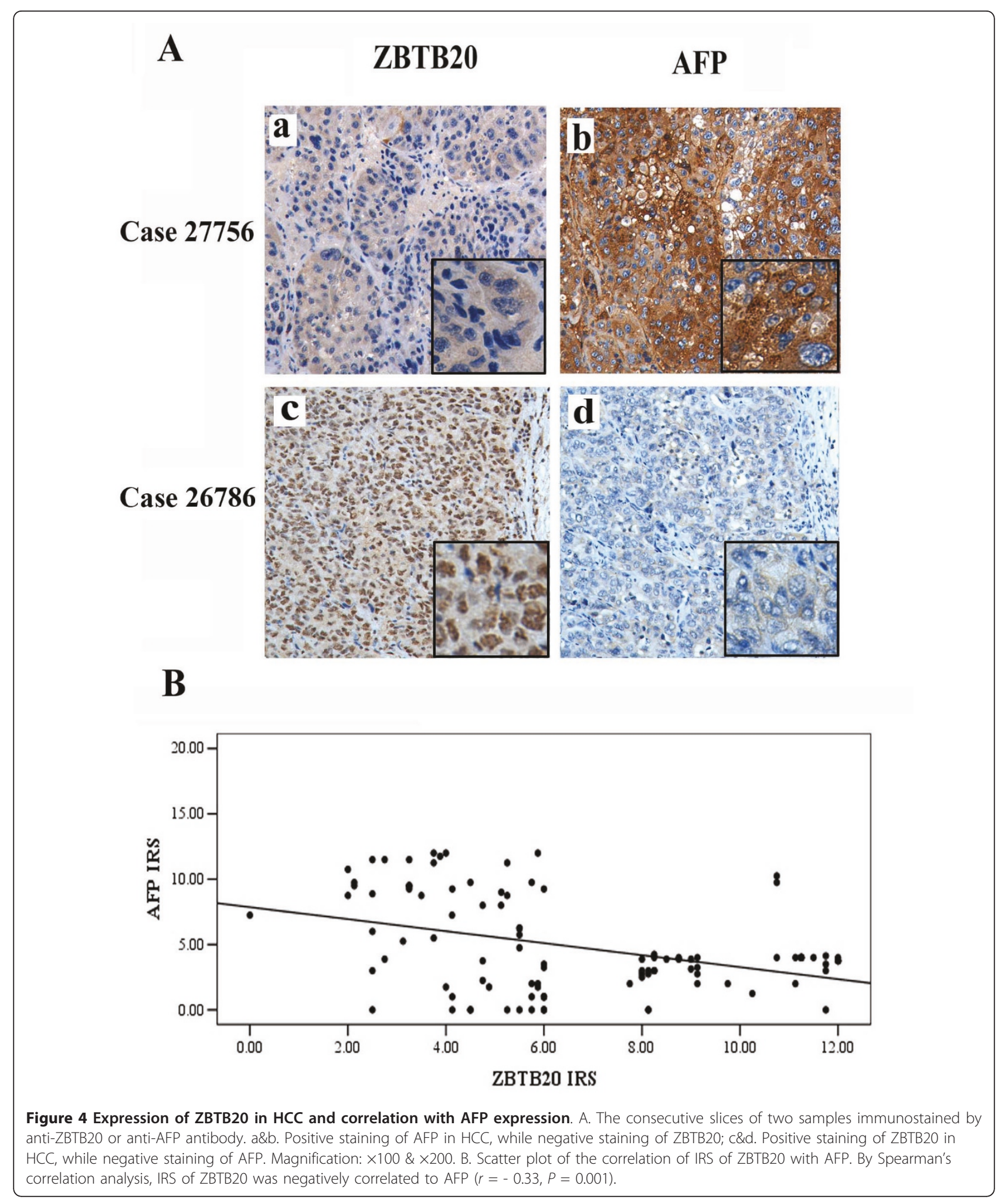



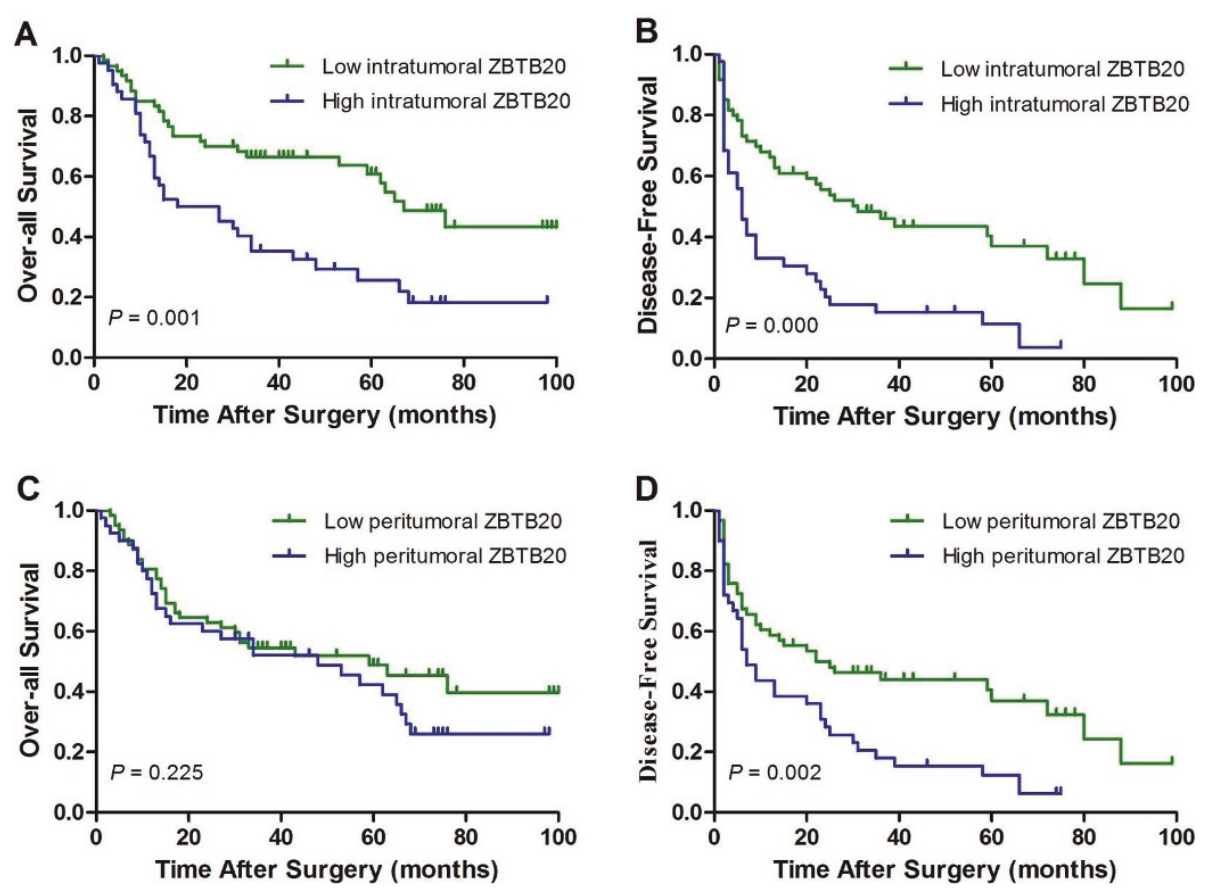

Figure 5 Cumulative overall and disease-free survival curves of patients with high or low intratumoral or peritumoral features. (A and B) Low intratumoral ZBTB20 was associated with prolonged overall and disease-free survival $(P=0.001$ and $P<0.001$, respectively). (C and D) Low peritumoral ZBTB20 was associated with disease-free survival $(P=0.002)$ but not with overall survival $(P=0.225)$.

Table 4 Univariate and Multivariate Analyses of Factors Associated With Survival and Recurrence

\begin{tabular}{|c|c|c|c|c|c|c|c|c|}
\hline \multirow[t]{3}{*}{ Factor } & \multicolumn{4}{|c|}{ OS } & \multicolumn{4}{|c|}{ DFS } \\
\hline & \multirow[b]{2}{*}{$\begin{array}{l}\text { Univariate } \\
\qquad P\end{array}$} & \multicolumn{3}{|c|}{ Multivariate } & \multirow[b]{2}{*}{$\begin{array}{l}\text { Univariate } \\
\qquad P\end{array}$} & \multicolumn{3}{|c|}{ Multivariate } \\
\hline & & $\begin{array}{l}\text { Hazard } \\
\text { Ratio }\end{array}$ & $95 \% \mathrm{Cl}$ & $P$ & & $\begin{array}{l}\text { Hazard } \\
\text { Ratio }\end{array}$ & $95 \% \mathrm{Cl}$ & $P$ \\
\hline Age: $\leq 50 v>50$ years & 0.603 & & & NA & 0.782 & & & NA \\
\hline Sex: female $v$ male & 0.197 & & & NA & 0.254 & & & NA \\
\hline Liver cirrhosis: no $v$ yes & 0.932 & & & NA & 0.194 & & & NA \\
\hline Tumor size: $\leq 50 \mathrm{v}>50 \mathrm{~mm}$ & 0.001 & 2.727 & $\begin{array}{l}1.326- \\
5.605\end{array}$ & 0.006 & 0.001 & 2.175 & $1.22-3.875$ & 0.008 \\
\hline AFP: $\leq 20 \vee>20 \mathrm{ng} / \mathrm{ml}$ & 0.051 & & & NA & 0.070 & & & NS \\
\hline HBsAg: positive $v$ negative & 0.141 & & & NA & 0.042 & & & NS \\
\hline TNM stage: $|-\|| v|| \mid$ & 0.002 & & & NS & ט 0.0001 & 1.982 & $\begin{array}{l}1.288- \\
3.366\end{array}$ & 0.005 \\
\hline Tumor number: single $v$ multiple & 0.017 & & & NS & 0.0001 & & & NS \\
\hline $\begin{array}{c}\text { Tumor encapsulation: complete } v \text { uncomplete } v \\
\text { no }\end{array}$ & 0.051 & & & NA & 0.065 & & & NA \\
\hline Vein invasion: yes $v$ no & 0.001 & 1.713 & $\begin{array}{l}0.927- \\
3.167\end{array}$ & 0.086 & v0.0001 & & & NS \\
\hline Intratumoral ZBTB20: low $v$ high & 0.001 & 1.952 & $\begin{array}{l}1.134- \\
3.359\end{array}$ & 0.016 & 0.0000 & 2.094 & $\begin{array}{l}1.296- \\
3.383\end{array}$ & 0.003 \\
\hline Peritumoral ZBTB20: low $v$ high & 0.225 & & & NA & 0.002 & & & NS \\
\hline
\end{tabular}

Abbreviations: OS, overall survival; DFS, disease-free survival; NA, not adopted; $\mathrm{HBsAg}$, hepatitis $\mathrm{B}$ s antigen; NS, not significant. 
patients with low intratumoral ZBTB20 $(7.72 \pm 2.9 v s$ $5.01 \pm 2.86, P<0.001)($ Table 5$)$.

\section{Discussion}

In this study, we examined ZBTB20 expression profiles and its correlations with clinicopathologic parameters and prognosis in HCC. Our data revealed that both mRNA and protein levels of ZBTB20 were significantly higher in HCC tissues than in the corresponding nontumor tissues and normal liver tissues.

We observed that increased expression of ZBTB20 in HCC was positively correlated with tumor vein invasion, recurrence and metastasis. Moreover, patients with high intratumoral ZBTB20 expression had significantly worse OS and DFS when compared with patients with low expression of ZBTB20. Multivariate analysis demonstrated that among the factors analyzed, intratumoral ZBTB20 expression was an independent prognostic factor for OS and DFS in patients with HCC. Meanwhile, tumor size, serum AFP, TNM stage, tumor number and vein invasion were all independent prognostic factors for OS; while tumor size, HBsAg positive, TNM stage, tumor number, vein invasion and peritumoral ZBTB20 expression were independent prognostic factors for DFS. These results clearly demonstrated that high ZBTB20 expression is associated with poor progression and unfavorable clinical outcome of HCC. This showed that high ZBTB20 expression in HCC is an indicator of poor prognosis.

Our earlier work demonstrated that ZBTB20 was a key repressor governing AFP gene transcription in postpartum liver. In this report, our data didn't show any relationship between ZBTB20 expression and serum AFP value. However, ZBTB20 and AFP expression, both of tumor tissue origin, were really inversely related (Figure 4). This was in keeping with the inconsistant relation between serum and tissue AFP level in HCC cases (unpublished data).

The close relationship between ZBTB20 expression and clinicopathological features predicted that ZBTB20 might boost carcinogenesis and tumor progression. Currently, several BTB/POZ-ZF proteins have been implicated in various cancers. For example, the BCL6 and PLZF proteins are causally involved in several types of

Table 5 Early Recurrence in HCC Patients

\begin{tabular}{ccccc}
\hline ZBTB20 density & \multicolumn{2}{c}{ Within $\mathbf{1 2}$ months } & t value & $\boldsymbol{P}$ \\
\cline { 2 - 3 } & $\begin{array}{c}\text { Recurrence } \\
(\mathbf{n}=\mathbf{5 1})\end{array}$ & $\begin{array}{c}\text { No recurrence } \\
(\mathbf{n}=\mathbf{5 1})\end{array}$ & & \\
\hline Intratumoral & $7.72 \pm 2.9$ & $5.01 \pm 2.86$ & 4.74 & 0.000 \\
Peritumoral & $2.98 \pm 1.70$ & $2.49 \pm 1.63$ & 1.484 & 0.141 \\
\hline
\end{tabular}

B-cell lymphomas and acute promyelocytic leukaemia [6-11]. NAC-1 is significantly overexpressed in ovarian serous carcinomas and intense NAC-1 immunoreactivity in primary tumors predicts early recurrence [26] whereas transgenic mice that overexpress Pokemon develop aggressive tumours [15]. Among these proteins, their BTB/POZ domains play a critical role in carcinogenesis and tumor progression. Some researches suggested that targeting the $\mathrm{BTB} / \mathrm{POZ}$ domain of BCL-6 caused apoptosis and cell cycle arrest, providing a novel approach for cancer therapy [7]. More recently, Cerchietti LC et al found that shock protein 90 (Hsp90) inhibitors selectively kill a subset of Diffuse Large B-cell Lymphomas (DLBCL) that are biologically dependent on the Bcl6 transcriptional repressor, through interrupting direct interaction between BCL- 6 and Hsp90 followed by accelerated BCL-6 degradation [43].

\section{Conclusion}

We demonstrated here, that ZBTB20 is overexpressed in a large proportion of patients with $\mathrm{HCC}$ and high ZBTB20 expression correlated with the disease progression and poor clinical outcome in HCC. Furthermore, ZBTB20 proved to be a risk factor for tumor recurrence and independent molecular marker of prognosis in HCC and may become a novel molecular target in the strategies for the prediction of tumor recurrence and prognosis or treatment of HCC.

\section{Additional material}

Additional file 1: Whole image of western blot showing ZBTB20 expression. ZBTB20 expression was detected in 4 pairs of $\mathrm{HCC}$ specimens, 3 HCC cell lines (HepG2, PLC and Huh-7) and 293T cell line transiently transfected with ZBTB20-expressing plasmid as well as its negative control. Molecular Marker. N: Non-tumor T: Tumor. L:293T cell line transiently transfected with ZBTB20-expressing plasmid; R: 293T cell line transiently transfected with empty plasmid. Arrowhead indicates the ZBTB20 ladder.

\section{Abbreviations}

HCC: Hepatocellular Carcinoma; BTB/POZ domain ZBTB20: Broad complex, tramtrack, and bric a brac; poxvirus and zinc finger; AFP: a feto-protein; $1 \mathrm{HC}$ : immunohistochemistry; HBV: Hepatitis B virus; DAB: Diaminobenzidine; BSA: Bovine serum albumin; EDTA: Ethylenediaminetetracetic acid; IRS: ImmunoReactive-Score; BCA: Bicinchoninic acid; PBS: Phosphate buffered solution; TBS(T): Triethanolamine-buffered saline(Tween-20); Tris: Tris(hydroxymethyl) aminomethane; SDS: Sodium dodecyl sulphate; OS: Overall survival; DFS: Disease-free survival.

Acknowledgements and funds

The study has been supported by the State Key Science \& Technology Project for Infectious Diseases (2008ZX10002), National Key Project of Scientific and Technical Supporting Programs (2008BAl63B03, 2006AA02A249) from State Ministry of Science \& Technology of China, and the foundation $(30772478,30921006,90713032,06 M A 154)$ from National Natural Science Foundation of China. 


\section{Author details}

IInternational Cooperation Laboratory on Signal Transduction, Eastern Hepatobiliary Surgery Institute, the Second Military Medical University, 225 Changhai Road, Shanghai, 200433, PR China. ²Department of Pathophysiology, Basic Medicine Institute, Second Military Medical University,800 Xiangyin Road, Shanghai, 200433, PR China. ${ }^{3}$ Department of Comprehensive Treatment II, Eastern Hepatobiliary Surgery Institute, the Second Military Medical University, 225 Changhai Road, Shanghai, 200433, PR China.

\section{Authors' contributions}

QW conducted the study and drafted the manuscript. YT conceived and designed the study. YR conducted the study and collected the clinical data. $L D, Z X, L T, D C$ and WZ analyzed and interpreted the data. HH and HW provided the administrative support. All the authors have read and approved the final version of the manuscript.

\section{Competing interests}

The authors declare that they have no competing interests.

Received: 27 January 2011 Accepted: 25 June 2011

Published: 25 June 2011

\section{References}

1. Max Parkin D, Freddie Bray, Ferlay J, Paola Pisani: Global Cancer Statistics, 2002. CA Cancer J Clin 2005, 55:74-108.

2. El-Serag BHashem, Klenhard Rudolph: Hepatocellular Carcinoma: Epidemiology and Molecular Carcinogenesis. Gastroenterology 2007, 132:2557-2576

3. Albagli O, Dhordain P, Deweindt C, Lecocq G, Leprince D: The BTB/POZ domain: a new protein-protein interaction motif common to DNA-and actin-binding proteins. Cell Growth Differ 1995, 6(9):1193-1198.

4. Kelly FKevin, Daniel MJuliet: POZ for effect - POZ-ZF transcription factors in cancer and development. Trends Cell Biol 2006, 16(11):578-587.

5. Stogios PJ, Downs GS, Jauhal JJ, Nandra SK, Privé GG: Sequence and structural analysis of BTB domain proteins. Genome Biol 2005, 6:R82

6. Polo JM, Dell'Oso T, Ranuncolo SM, Cerchietti L, Beck D, Da silva GF, Prive Gibert G, Licht JD, Melnick A: Specific peptide interference reveals BCL6 transcriptional and oncogenic mechanisms in B-cell lymphoma cells. Nat Med 2004, 10:1329-1335.

7. Phan RT, Dalla-Favera R: The BCL6 proto-oncogene suppresses $\mathrm{p} 53$ expression in germinal-centre B cells. Nature 2004, 432:635-639.

8. Margalit O, Amram H, Amariglio N, Simon AJ, Shaklai S, Granot G, Minsky N, Shimoni A, Harmelin A, Givol D, Shohat M, Oren M, Rechavi G: BCL6 is regulated by $\mathrm{p} 53$ through a response element frequently disrupted in $\mathrm{B}$ cell non-Hodgkin lymphoma. Blood 2006, 107:1599-1607.

9. Ranuncolo SM, Polo JM, Dierov J, singer M, Kuo T, Greally J, Green R, Carroll M, Melnick A: Bcl-6 mediates the germinal center B cell phenotype and lymphomagenesis through transcriptional repression of the DNA-damage sensor ATR. Nat Immunol 2007, 8:705-714.

10. Yeyati PL, Shaknovich R, Boterashvili S, Li J, Ball HJ, Waxman S, Burchenal KN, Dmitrovsky ED, Zelent A, Licht JD: Leukemia translocation protein PLZF inhibits cell growth and expression of cyclin A. Oncogene 1999, 18:925-934.

11. Costoya JA, Pandolfi PP: The role of promyelocytic leukemia zinc finger and promyelocytic leukemia in leukemogenesis and development. Curr Opin Hematol 2001, 8:212-217.

12. Felicetti $F$, Errico MC, Bottero L, Segnalini P, Stoppacciaro A, Biffoni M, Felli N, Mattia G, Petrini M, Colombo MP, Peschle C, Care A: The promyelocytic leukemia zinc finger-microRNA-221/-222 pathway controls melanoma progression through multiple oncogenic mechanisms. Cancer Res 2008, 68:2745-2754

13. Shiraishi K, Yamasaki K, Nanba D, Inoue H, Hanakawa Y, Shirakata Y, Hashimoto K, Higashiyama S: Pre-B-cell leukemia transcription factor 1 is a major target of promyelocytic leukemia zinc-finger-mediated melanoma cell growth suppression. Oncogene 2007, 26:339-348.

14. Parrado A, Robledo M, Moya-Quiles MR, Marin LA, Chomienne C, Padua RA, Alvarez-lopez MR: The promyelocytic leukemia zinc finger protein downregulates apoptosis and expression of the proapoptotic BID protein in lymphocytes. Proc Natl Acad Sci USA 2004, 101:1898-1903.
15. Maeda T, Hobbs RM, Merghoub T, Merghoub T, Guernah I, Zelent A Cordon-cardo C, Teruya-Feldstein , Pandolfi PP: Role of the protooncogene Pokemon in cellular transformation and ARF repression. Nature 2005, 433:278-285.

16. Maeda T, Hobbs RM, Pandolfi PP: The transcription factor Pokemon: a new key player in cancer pathogenesis. Cancer Res 2005, 65:8575-8578.

17. Aggarwal A, Hunter WJ, Aggarwal H, Silva ED, Davey MS, Murphy RF, Agrawal DK: Expression of leukemia/lymphoma-related factor (LRF/ POKEMON) in human breast carcinoma and other cancers. Exp Mol Pathol 2010, 89(2):140-8, Epub 2010 May 21.

18. Maeda T, Merghoub T, Hobbs RM, Dong L, Maeda M, Zakrzewski J, R Brink MRM, Zelent A, Shigematsu H, Akashi K, Teruya-Feldstein J, Cattoretti G, pandolfi PP: Regulation of B versus T lymphoid lineage fate decision by the proto-oncogene LRF. Science 2007, 316:860-866.

19. Mondal AM, Chinnadurai S, Datta K, Chauhan SS, Sinha S, Chattopadhyay P: Identification and functional characterization of a novel unspliced transcript variant of HIC-1 in human cancer cells exposed to adverse growth conditions. Cancer Res 2006, 66:10466-10477.

20. Waha A, Waha A, Koch A, Meyer-Puttlitz B, Weqqen S, Sorensen N, Tonn JC, Albrecht S, Goodyer CG, Wiestler OD, Pietsch T: Epigenetic silencing of the HIC-1 gene in human medulloblastomas. J Neuropathol Exp Neurol 2003, 62:1192-1201.

21. Nishida N, Nagasaka T, Nishimura T, Ikai I, Boland CR, Goel A: Aberrant methylation of multiple tumor suppressor genes in aging liver, chronic hepatitis, and hepatocellular carcinoma. Hepatology 2008, 47:908-918.

22. Hayashi M, Tokuchi Y, Hashimoto T, Hayashi S, Nishida K, Ishikawa Y, Nakagawa K, Tsuchiya S, Tsuchiya E: Reduced HIC-1 gene expression in non-small cell lung cancer and its clinical significance. Anticancer Res 2001, 21:535-540.

23. Nicoll G, Crichton DN, McDowell HE, Kernohan N, Hupp TR, Thompson AM: Expression of the Hypermethylated in Cancer gene (HIC-1) is associated with good outcome in human breast cancer. Br J Cancer 2001, 85:1878-1882.

24. Mackler SA, Korutla L, Cha XY, Koebbe MJ, Fournier KM, Bowers MS, Kalivas PW: NAC-1 is a brain POZ/BTB protein that can prevent cocaineinduced sensitization in the rat. J Neurosci 2000, 20:6210-6217.

25. Korutla L, Neustadter JH, Fournier KM, Mackler SA: NAC1, a POZ/BTB protein present in the adult mammalian brain, triggers apoptosis after adenovirus-mediated overexpression in PC-12 cells. Neurosci Res 2003, 46:33-39.

26. Nakayama K, Nakayama N, Davidson B, Sheu JJ, Jinawath N, Santillan A, Salani R, Bristow RE, Morin PJ, Kurman RJM, Wang TL, Shih leM: A BTB/POZ protein, NAC-1, is related to tumor recurrence and is essential for tumor growth and survival. Proc Natl Acad Sci USA 2006, 103:18739-18744

27. Yeasmin S, Nakayama K, Ishibashi M, Claes G: Trope, Tian-li Wang, leming Shih: Expression of the bric-a-brac tramtrack broad complex protein NAC-1 in cervical carcinomas seems to correlate with poorer prognosis. Clin Cancer Res 2008, 14:1686-1691.

28. Davidson B, Berner A, Trope' CG, Wang TL, Shih leM: Expression and clinical role of the bric-a-brac tramtrack broad complex/poxvirus and zinc protein NAC-1 in ovarian carcinoma effusions. Hum Pathol 2007, 38:1030-1036.

29. Nakayama K, Nakayama N, Wang TL, Shih leM: NAC-1 controls cell growth and survival by repressing transcription of Gadd45GIP1, a candidate tumor suppressor. Cancer Res 2007, 67:8058-64.

30. Prokhortchouk A, Sansom O, Selfridge J, Caballero IM, Salozhin S, Aithozhina D, Cerchietti L, Meng FG, Augenlicht LH, Mariadason JM, Hendrich B, Melnick A, Prokhortchouk E, Clarke A, Bird A: Kaiso-deficient mice show resistance to intestinal cancer. Mol Cell Biol 2006, 26:199-208,

31. Van Roy FM, McCrea PD: A role for Kaiso-p120ctn complexes in cancer? Nat Rev Cancer 2005, 5:956-964.

32. Daniel JM, Reynolds AB: The catenin p120 (ctn) interacts with Kaiso, a novel BTB/POZ domain zinc finger transcription factor. Mol Cell Biol 1999, 19:3614-3623.

33. Soubry A, van Hengel J, Parthoens E, Colpaert C, Van Marck E, Waltrgny D, Reynolds $A B$, van Roy F: Expression and nuclear location of the transcriptional repressor Kaiso is regulated by the tumor microenvironment. Cancer Res 2005, 65:2224-2233.

34. Zhang W, Mi J, Li N, Sui L, Wan T, Zhang J, Chen T, Cao X: Identification and Characterization of ZBTB20, a Novel Human BTB/POZ Zinc Finger 
Protein Sharing Homology to BCL-6. Biochem Biophys Res Commun 2001, 282:1067-1073

35. Mitchelmore C, Kjaerulff KM, Pedersen HC, Nielsen JV, Rasmussen TE, Fisker MF, Finsen B, Pedersen KM, Jensen NA: Characterization of Two Novel Nuclear BTB/POZ Domain Zinc Finger Isoforms. J Biol Chem 2002, 277:7598-7609.

36. Harboe TL, Tümer $Z$, Hansen $C$, Jensen NA, Tommerup N: Assignment of the human zinc finger gene, ZNF288, to chromosome 3 band $q 13.2$ by radiation hybrid mapping and fluorescence in situ hybridisation. Cytogenet Cell Genet 2000, 89:156-157.

37. Nielsen JV, Nielsen FH, Ismail R, Noraberg J, Jensen NA: Hippocampus-like corticoneurogenesis induced by two isoforms of the BTB-zinc finger gene Zbtb20 in mice. Development 2007, 134:1133-1140.

38. Xie Z, Zhang H, Tsai W, Zhang Y, Du Y, Zhong J, Szpirer C, Zhu M, Cao X, Barton MC, Grusby MJ, Zhang WJ: Zinc finger protein ZBTB20 is a key repressor of alpha-fetoprotein gene transcription in liver. Proc Natl Acad Sci USA 2008, 105:10859-10864.

39. Sutherland AP, Zhang H, Zhang Y, Michaud M, Xie Z, Patti ME, Grusby MJ, Zhang WJ: Zinc finger protein Zbtb20 is essential for postnatal survival and glucose homeostasis. Mol Cell Biol 2009, 29:2804-2815.

40. Sobin LH, Gospodarowicz MK, Wittekind CH, Eds: TNM Classification of Malignant Tumors. New York, Wiley-Liss, Inc.; 6 2002, 81-83.

41. Dong LW, Kong XN, Yan HX, Yu LX, Chen L, Yang W, Liu Q, Huang DD, Wu MC, Wang HY: Signal regulatory protein alpha negatively regulates both TLR3 and cytoplasmic pathways in type I interferon induction. Mol Immunol 2008, 45:3025-3035.

42. Poon RT, Fan ST, Ng IO, Lo CM, Liu CL, Wong J: Different risk factors and prognosis for early and late intrahepatic recurrence after resection of hepatocellular carcinoma. Cancer 2000, 89:500-507.

43. Cerchietti LC, Lopes EC, Yang SN, Hatzi K, Bunting KL, Tsikitas LA, Mallik A, Robles Al, Walling J, Varticovski L, Shaknovich R, Bhalla KN, Chiosis G, Melnick A: A purine scaffold Hsp90 inhibitor destabilizes BCL-6 and has specific antitumor activity in BCL-6-dependent B cell lymphomas. Nat Med 2009, 15:1369-1376.

Pre-publication history

The pre-publication history for this paper can be accessed here: http://www.biomedcentral.com/1471-2407/11/271/prepub

doi:10.1186/1471-2407-11-271

Cite this article as: Wang et al: Zinc finger protein ZBTB20 expression is increased in hepatocellular carcinoma and associated with poor prognosis. BMC Cancer 2011 11:271

\section{Submit your next manuscript to BioMed Central and take full advantage of:}

- Convenient online submission

- Thorough peer review

- No space constraints or color figure charges

- Immediate publication on acceptance

- Inclusion in PubMed, CAS, Scopus and Google Scholar

- Research which is freely available for redistribution

Submit your manuscript at www.biomedcentral.com/submit 